
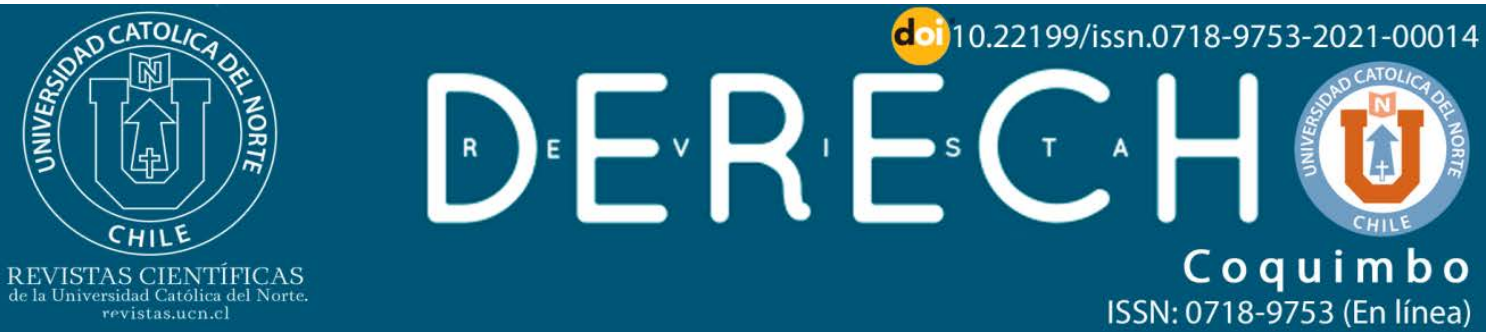

\title{
La caución como requisito para conceder una medida caute- lar: su no exigibilidad en materia contenciosa administrativa
}

\section{A bond as requesting in an interim injunctive measure: its non en- forceability to suspend an administrative act}

\author{
Andrés Bordalí Salamanca' (iD) https://orcid.org/0000-0002-5126-8037 \\ 1 Universidad Austral de Chile, Valdivia, Chile. Profesor de derecho procesal. Abogado. Doctor \\ en Derecho y Economía Públicos, Universidad de Valladolid, España. \\ @abordali@uach.cl \\ (cc) BY
}

\section{Resumen:}

Se examina el derecho fundamental a la tutela judicial y la exigencia de que ésta sea efectiva. Esencial en ello será contar con herramientas cautelares necesarias y adecuadas que permitan que los derechos $e$ intereses de las personas resulten plenamente satisfechos en el proceso judicial. Se abordan en el trabajo las principales limitaciones para que las personas cuenten con herramientas cautelares en el contencioso administrativo, al serle aplicable a éste supletoriamente la legislación procesal civil. Especial consideración se realiza sobre la exigencia de una caución al solicitarse una medida cautelar de suspensión del acto administrativo.

Palabras Clave: Tutela judicial efectiva;

Tutela cautelar; Litigación administrativa.

\begin{abstract}
:
The fundamental right to judicial protection and the requirement that it be effective are examined. Because the existence of appropriate interim injunctions that allow the rights and interests of the people to be fully satisfied in the judicial process is essential to its effectiveness, this paper addresses the main limitations of injunctive measures in administrative justice based in the supplemental application of civil procedure legislation. Special attention is paid to the requirement of a bond when requesting an injunctive measure to suspend an administrative act.

Keywords: Effective judicial protection; Interim injunctions; Administrative litigation.
\end{abstract}


La caución como requisito para conceder una medida cautelar...

\section{Introducción}

En los últimos tiempos, han aumentado las actividades económicas reguladas por el Estado. En particular, la Administración del Estado tiene hoy en día exorbitantes poderes que muchas veces no se ejercitan de una manera acorde con el ordenamiento jurídico, afectando a los derechos e intereses legítimos de las empresas y de los administrados en general.

Frente a ese actuar ilegal de la Administración, los particulares afectados en sus derechos e intereses legítimos pueden reclamar ante los tribunales de justicia, ejerciendo el derecho fundamental a la tutela judicial.

Sin embargo, ese derecho a la tutela judicial para los administrados chilenos tendrá ciertas particularidades. En muchos casos, será un tribunal civil el que conocerá la pretensión de ese sujeto, pues como sabemos no tenemos tribunales de lo contencioso administrativo. En algunos casos, conocerán del referido contencioso algunos tribunales administrativos especiales. En muchos casos, esos tribunales tramitarán la pretensión formulada por el actor de acuerdo a un proceso civil y todas las reglas comunes del juicio ordinario civil. Entre esas reglas comunes, están las referidas a las medidas precautorias como expresión de la tutela cautelar civil.

Desde hace un tiempo, la doctrina y jurisprudencia nacional y comparada reclaman que unas adecuadas medidas cautelares son esenciales para que la tutela judicial pueda efectivamente dar amparo a los derechos e intereses legítimos del actor, que tiene al sistema jurídico de su lado y necesidad imperiosa de amparo. Los particulares tienen, por tanto, dentro de su derecho fundamental a la tutela judicial, un derecho a contar con una batería adecuada de instrumentos cautelares para así obtener una tutela judicial efectiva.

De acuerdo con lo señalado, en el contencioso administrativo de nulidad chileno, los demandantes, por regla general, tendrán que recurrir a las reglas de las medidas precautorias civiles del Código de Procedimiento Civil (Ley N 15.552, 1902), pues esa es la regulación legal supletoria a aplicar. Entre éstas, no está la suspensión del acto administrativo mientras se tramita el proceso. Pero el Código de Procedimiento Civil (1902, art. 298) autoriza al juez civil a decretar medidas atípicas o innominadas. Entre ellas, podrá estar la suspensión del acto administrativo.

Sin embargo, en muchos casos los jueces civiles que conocen de ese contencioso administrativo, para decretar una medida cautelar innominada, exigen que se rinda una caución suficiente. Esta caución presenta varios problemas. En primer lugar, si es que el juez determina constituir caución, puede darse el caso que el actor no tenga bienes o capacidad económica para constituir dicha caución, y por tanto no podrá paralizar los efectos del acto administrativo impugnado y que le causa un per- 
juicio. Pero, por otra parte, la experiencia forense demuestra que los jueces civiles, frente a un contencioso administrativo de nulidad, no cuentan con parámetros para determinar el monto de dicha caución y frente a esa situación, optan por no conceder la medida cautelar.

En el contencioso administrativo, la suspensión del acto administrativo debería proceder siempre que la existencia del derecho o interés legítimo del actor parezca verosímil. Por regla general, ese otorgamiento de la medida no debería venir aparejada a la exigencia de constituir una caución. Solo así ese actor privado obtendría una tutela judicial efectiva para su derecho o interés.

De acuerdo con lo anterior, lo que corresponde, de lege ferenda, es que se regule expresamente la medida cautelar de suspensión del acto administrativo y los presupuestos y condiciones para otorgarla, en principio sin exigir caución.

Sin embargo, mientras el legislador no regule lo anterior, corresponde a los jueces civiles y administrativos que conocen del contencioso administrativo de nulidad, interpretar las reglas de las medidas precautorias del Código de Procedimiento Civil (1902) del modo más favorable al derecho fundamental a la tutela judicial del actor privado. Analizando cada caso en concreto, ante un derecho subjetivo o interés legítimo que aparece necesitado de tutela, ese juez, en principio, no debería exigir una caución para decretar la suspensión del acto administrativo impugnado.

\section{El derecho fundamental a la tutela judicial en el derecho chileno}

El derecho a la tutela judicial ha recibido reconocimiento doctrinal y jurisprudencial en el derecho chileno. No tiene un reconocimiento palmariamente explícito en nuestro orden constitucional, pero se lo ha entendido como un derecho implícito (García Pino. y Contreras Vásquez, 2013, pp. 235 y 236) que arranca del art. 19 № 3 del Código de Procedimiento Civil (1902). Para ver cómo ha sido el reconocimiento que el derecho a la tutela judicial ha recibido en la doctrina nacional, y sobre todo en la jurisprudencia del Tribunal Constitucional, remito a Bordalí Salamanca (2011a), passim.

Los principales contenidos de esta garantía constitucional, son el derecho a acceder a un tribunal de justicia solicitando la tutela de un derecho subjetivo o interés legítimo afirmado como propio. Asimismo, un derecho a que el tribunal resuelva sobre esa solicitud de tutela, si concurren los presupuestos legales para obligar a tramitar el proceso y fallar sobre el fondo de la pretensión deducida (Bordalí Salamanca, 2016, pp. 187 y 193).

Sin embargo, la doctrina y jurisprudencia más contemporáneas han avanzado hacia otros componentes del derecho a la tutela judicial, que miran a que la tutela que debe dar el Estado sea realmente efectiva. Entre esos derechos que entran en la 
esfera de la tutela judicial efectiva, destacan: a) Un derecho a la inmodificabilidad de las resoluciones judiciales (o respeto de la cosa juzgada); b) un derecho a disponer de medidas cautelares, y c) un derecho a la ejecución de las resoluciones judiciales (Bordalí Salamanca, 2016, p. 193).

Señalado lo anterior, una primera cuestión que surge respecto a la tutela judicial es si opera en todos los campos de la justicia o solo en algunos. En otras ocasiones, me he referido a que como este derecho fundamental se articula para solicitar al Estado la tutela de derechos subjetivos e intereses legítimos de quien afirma ser su titular, lo que puede incluir hipótesis de derechos e intereses individuales, así como colectivos o difusos, no tiene aplicación en el campo procesal penal. La negativa de incluir al proceso penal en el ámbito del derecho a la tutela judicial, tiene como fundamento en que en ese caso el acusador no solicita tutela para un derecho o interés de su titularidad, sino que se pone en una posición y ejerce una función que siempre en materia penal es pública.

Sin embargo, esta tesis que excluye del derecho a la tutela judicial al actor penal no ha sido seguida en general por el Tribunal Constitucional chileno, quien considera que el derecho rige en todos los ámbitos del derecho, incluido el penal (Bordalí Salamanca, 2011b, p. 523).

Agregaré, que la doctrina contemporánea destaca que desde la existencia de este derecho fundamental a la tutela judicial, la labor del legislador procesal y del juez ha cambiado notablemente. El juez ya no puede ser visto como un mero pacificador que resuelve un conflicto entre partes, sino que debe velar por la idoneidad de la prestación jurisdiccional.

Es decir, el deber del juez, así como del legislador, al instituir la técnica procesal adecuada, está vinculado al derecho fundamental a la efectividad de la tutela jurisdiccional, comprendido como un derecho necesario para que se dé protección a todos los otros derechos. (Marinoni, 2007, p. 231)

Esa distinta perspectiva le impone al juez un rol más activo en el proceso, ya sea interpretando la ley siempre en un sentido más favorable a la plena tutela de los derechos fundamentales de las partes, así como tramitando el proceso para que pueda determinarse la verdad de lo discutido en el menor tiempo posible.

Por otra parte, se debe consignar que el derecho a la tutela judicial es un derecho de tipo prestacional que necesita de configuración y desarrollo legal. Como será el legislador el que en definitiva dé vida al derecho, esa labor legislativa si bien puede limitar o condicionar el ejercicio del derecho, no puede hacerlo de modo de imponer obstáculos o trabas arbitrarias o caprichos que impidan la tutela garantizada constitucionalmente. 


\section{El derecho a la efectividad de las resoluciones judiciales como componente de la tutela judicial}

\subsection{El derecho a la tutela cautelar y su importancia}

Se ha entendido en el derecho comparado, como por ejemplo en el derecho español, un referente directo para nuestro desarrollo del derecho a la tutela judicial, que esta garantía constitucional incluye el derecho a que el legislador prevea medidas cautelares para que los jueces puedan adoptarlas. Asimismo, se ha señalado que se tiene derecho a que el juez resuelva sobre las peticiones de medidas cautelares razonadamente, y no de forma arbitraria y carente de fundamento.

El Tribunal Constitucional español, ha señalado que la tutela judicial no es tal sin medidas cautelares que aseguren el efectivo cumplimiento de la futura resolución definitiva que recaiga en el proceso (véanse las sentencias del Tribunal Constitucional de España nos. 78/1996 y 27/1995, entre otras). El Legislador, debe disponer de medidas cautelares pues ello forma parte del derecho a la tutela judicial (véanse las sentencias del Tribunal Constitucional de España nos.m 78/1996 y 218/1994, entre otras).

La Corte costituzionale (Sentencia 190/1985), a su vez, ha señalado que la tutela cautelar constituye un componente esencial del derecho a la tutela judicial, que no puede ser eliminada por el legislador. En virtud de tal jurisprudencia, la doctrina afirma categóricamente que la tutela cautelar constituye un elemento esencial e insuprimible de la tutela jurisdiccional (Cipriani, 2007, p. 295).

Aún más, hoy en Italia se sostiene que la tutela cautelar tiene cobertura constitucional y, además, un claro reconocimiento en la jurisprudencia de la Corte de Justicia de la Unión Europea. Se trataría de una aproximación a la que se arriba guiados por el principio de efectividad que ha sido definido como un super-principio (Tommaseo, 2008, p. 171).

El valor que debe ser atribuido a la tutela cautelar, debe entenderse en la necesidad de las partes de un proceso judicial de recibir una tutela judicial que ampare a los derechos e intereses necesitados de tutela, de una manera efectiva y en sus propios términos.

Y todo ello estará en directa relación con el tipo de procedimiento donde debe dictarse la medida cautelar, y de cómo se comporta en la práctica tal procedimiento. Así, es evidente que si la medida se dicta dentro de un procedimiento ordinario que estructuralmente funciona con cierta lentitud y que en su práctica ese retardo se transforma en una patología, será tanto más necesario que el procedimiento cautelar funcione bien (Cipriani, 2007, p. 297). 
El objetivo que busca el proceso cautelar, es permitir que la sentencia que dictará el juez referida a la tutela de un determinado derecho subjetivo o interés legítimo de una persona, pueda cumplirse en sus propios términos y no se haga así ilusoria producto de sucesos que hayan acaecido durante el normal iter del proceso.

Además de un instrumento al servicio de la tutela de los derechos e intereses legítimos de los individuos, se ha destacado el carácter público que tiene la tutela cautelar. Con su adecuado reconocimiento y correcta utilización, se trata de impedir, como expresara Calamandrei (1996):

...que la soberanía del Estado, en su más alta expresión que es la de la justicia, se reduzca a ser una tardía e inútil expresión verbal, una vana ostentación de lentos mecanismos destinados, como los guardias de la ópera bufa, a llegar siempre demasiado tarde. (p. 140)

\subsection{La tutela cautelar en el Código de Procedimiento Civil}

En materia civil, en el derecho chileno, la expresión más típica de tutela cautelar corresponde a las denominadas medidas precautorias, reguladas por el art. 290 y siguientes del Código de Procedimiento Civil (1902). Estas, se encuentran establecidas con el objeto de asegurar el resultado del proceso principal, ya iniciado o a iniciar.

La importancia que tiene un análisis de la tutela cautelar en sede civil, es que ella tiene aplicación supletoria en todo tipo de procesos, incluido el contencioso administrativo y la responsabilidad civil que emana de un delito y que se puede ventilar ante el propio juez penal chileno.

Tradicionalmente, se ha entendido que son dos los presupuestos que deben concurrir siempre para que el tribunal pueda dictar una medida cautelar. El fumus boni iuris (o apariencia de buen derecho) y el periculum in mora (o peligro en la demora), aunque deberá incluirse otro presupuesto de mayor desarrollo en los tiempos actuales, producto del impacto que en el sistema jurídico tienen los derechos fundamentales, como es el principio de proporcionalidad. Finalmente, hay que agregar que eventualmente puede exigirse una caución o contra cautela.

Para poder decretarse una medida cautelar, deben existir antecedentes que hagan verosímil que el derecho está del lado de quien demanda y solicita tal medida. Para ello, el solicitante de la medida deberá "...acompañar comprobantes que constituyan [...] presunción grave del derecho que se reclama..." (Código de Procedimiento Civil, 1902, art. 298).

Esos comprobantes, normalmente serán instrumentos públicos o privados que corresponde al solicitante de la medida aportar en el proceso. Sin embargo, se 
ha dicho razonadamente que no está restringido solo a esos instrumentos, sino que puede consistir en cualquier medio de prueba (Cortéz Matcovich, 2017, p. 94).

Respecto al peligro en la demora, el Código de Procedimiento Civil señala algunas hipótesis de peligro. Así, a propósito del secuestro judicial se señala que procede éste cuando "... haya motivo de temer que se pierda o deteriore en manos de la persona que, sin ser poseedora de dicha cosa, la tenga en su poder" (Código de Procedimiento Civil, 1902, art. 291).

En el caso de nombramiento de interventor, la ley habla de "...justo motivo de temor..." (Código de Procedimiento Civil, 1902, art. 293, no. 2); "justo motivo de temer que se destruya o deteriore la cosa sobre que versa el juicio, o que los derechos del demandante puedan quedar burlados..." (Código de Procedimiento Civil, 1902, art. 293, no. 5).

En la situación de la retención de dineros, la ley expresa el peligro en la demora como cuando las facultades del demandado "...no ofrezcan suficiente garantía, o haya motivo racional para creer que procurará ocultar sus bienes..." (Código de Procedimiento Civil, 1902, art. 295).

Respecto a la medida de prohibición de celebrar actos o contratos, el peligro está representado por unas facultades del demandado que no ofrecen "...suficiente garantía para asegurar el resultado del juicio" (Código de Procedimiento Civil, 1902, art. 296).

El peligro de daño puede consistir en infructuosidad, o bien en un peligro derivado de la tardanza en la prestación judicial.

En algunas ocasiones lo importante es que la medida cautelar asegure de manera pronta la existencia de bienes o de la cosa objeto de la demanda en vista de la futura ejecución. En otras, en cambio, la medida cautelar lo que busca es acelerar provisoriamente la satisfacción de la pretensión deducida, porque de esperarse el completo desarrollo del juicio se pueden producir en el demandante perjuicios graves. (Marín González, 2016, pp. 320 y 321)

¿Cómo puede ser concebido con un carácter general el peligro en la demora? Un sector de la doctrina, considera que una de las hipótesis de peligro es la irreversibilidad de un daño o lesión (Ortells Ramos y Calderón Cuadrado, 1996, p. 15). Así, en nuestro país, Cortéz Matcovich (2017), a propósito del periculum in mora en sede civil, habla de "daño irreparable" (p. 101). Algunos autores, restringen la idea de daño irreparable solo al daño en la tardanza y no referido a la infructuosidad (Ortells Ramos, 2007 , p. 937). Otros agregan que la irreparabilidad del daño no se exige en aquellos casos de daños meramente económicos, o cuando consista en una falta de satisfacer sumas de dinero (Casetta y Fracchia, 2017, p. 215). 
¿Cuándo podemos entender que el daño es irreparable? En ocasiones se lo asocia con la idea de irreversibilidad. Eso puede ser con un carácter total o parcial, es decir, cuando el bien ya no puede ofrecer en absoluto la utilidad que brinda y no hay mecanismo alguno que pueda recuperarla, o bien, cuando ella puede ser relativamente restituida, pero ello es muy difícil materialmente o puede ser realizada, pero a un costo económico excesivo carente de proporcionalidad.

En el derecho comparado, Rapisarda Sassoon (1987, p. 144), comentando lo dispuesto en el artículo 700 del Código de Procedimiento Civil italiano, señala que ese daño irreparable se podría concretar si en el tiempo necesario para obtener la tutela ordinaria, puede verificarse una total imposibilidad de satisfacción del derecho mediante los remedios ordinarios de reintegración en forma específica o de resarcimiento por equivalente.

Avanzando en esta apretada síntesis de los presupuestos de la tutela cautelar civil, se debe tener en consideración que, a raíz de que el Código de Procedimiento Civil (1902, art. 298), expresa que las medidas precautorias se limitarán a los bienes necesarios para responder a los resultados del juicio, todas las medidas precautorias (y las cautelares en general) deben estar informadas por el principio de proporcionalidad.

El principio de proporcionalidad, está en estrecha relación con el respeto de los derechos fundamentales de los ciudadanos y el Estado de derecho.

Se trata de un principio que nace del Derecho de Policía y el Derecho Administrativo, pero hoy en día rige toda la actuación de los poderes públicos, incluido los tribunales de justicia.

Su sentido, es limitar el poder estatal y resaltar la plena vigencia de los derechos fundamentales de las personas. Se trata que toda intervención del poder público debe reducirse al mínimo indispensable. De este modo, "...la libertad ly los derechos] del individuo es un principio, en tanto que la restricción de ésta una excepción [...] la intervención pública debe ser excepcional..." (Arnold, Martínez Estay y Zúñiga Urbina, 2012, p. 69).

Ha dicho en nuestro país Marín González (2016) en la más completa obra sobre medidas cautelares existente hoy en día en el derecho chileno, que:

...las medidas cautelares deben ser utilizadas como herramientas verdaderamente útiles en el proceso; como armas que resguardan los legítimos intereses del demandante para que no se burle el cumplimiento de la sentencia que, en su momento, se dicte en su favor. No deben ser utilizadas para menoscabar los también intereses legítimos del demandado. ( $p$. 308) 
Todo lo dicho anteriormente, se explica porque una medida cautelar que recae sobre un bien o derecho del demandado importa per se una restricción de un derecho fundamental, sin que tenga como base una decisión judicial que se funde en la verdad plenamente establecida en el proceso. Para que esa limitación que toda medida cautelar importa para los derechos fundamentales del demandado sea racional y justa, debe evitar al máximo posible daños a los mismos.

La jurisprudencia y doctrina chilenas, han recogido el principio de proporcionalidad de conformidad a la construcción del mismo que durante años ha ido consolidando el Tribunal Constitucional Federal alemán. Este tribunal lo ha entendido en un doble sentido: a) amplio y b) estricto.

En un sentido amplio, proporcionalidad significa que el medio previsto por la autoridad debe ser idóneo o adecuado (adecuación), y necesario o exigible para alcanzar el objetivo propuesto (exigibilidad). Que sea adecuado o idóneo, viene a significar que con él puede lograrse el resultado deseado. Que sea necesario o exigible, significa que la autoridad no habría podido optar por un medio distinto, igualmente eficaz, que no limitara o que lo hiciera en menor grado, el derecho fundamental de que se trate.

En un sentido estricto, la proporcionalidad viene a significar que la gravedad de la lesión para el derecho fundamental y la trascendencia de sus razones justificativas han de estar en adecuada proporción.

El Tribunal Constitucional Federal alemán, ha señalado que cuanto más sensible sea la intrusión de una medida en la posición jurídica de la persona, más relevantes deberán ser los intereses de la comunidad que se hallan en colisión con ella, sobre este punto véase Bordalí Salamanca (2002, p. 68 y ss.)

En materia procesal civil, los derechos fundamentales involucrados suelen ser el derecho de propiedad y el derecho a desarrollar libremente actividades económicas. En materia administrativa, se conjuga un interés público gestionado por la Administración del Estado, con los derechos fundamentales de terceros interesados en el proceso.

Es deber del tribunal, por tanto, ponderar los intereses en conflicto y valorar la parcial prevalencia de unos sobre otros, al momento de acceder o no a una medida cautelar (Bordalí Salamanca y Ferrada Bórquez, 2009, p. 199). Y lo más relevante en este punto: deberá decretar la medida menos intrusiva para los derechos fundamentales posiblemente afectados.

En relación a esta idea de mínima intrusión en la esfera privada o patrimonial del demandado con la medida cautelar, un sector de la doctrina nacional establece como criterio general que debe guiar la adopción de una medida cautelar el de mí- 
La caución como requisito para conceder una medida cautelar...

nima injerencia. Cortéz Matcovich (2017, p. 56) desarrolla con detalle este principio, el que no es otra cosa que el de proporcionalidad como ha sido explicado acá.

\section{Posibles limitaciones legislativas y judiciales a disponer de medi- das cautelares}

Las medidas cautelares siempre deben ser decretadas por el tribunal que conoce la causa. Eso expresa que el juez desarrolla en este punto una actividad propia de la función jurisdiccional: subsumir unos hechos determinados en un supuesto fáctico normativo. Pero en materia de tutela cautelar los hechos son bastante complejos por una serie de razones. Quizás la complejidad más relevante, viene dada porque los hechos no han sido determinados totalmente en el proceso, es decir, no existe un establecimiento verídico de los hechos con base a las probanzas rendidas en el juicio. Pero, además, dicha complejidad viene dada porque la tutela cautelar significa tomar en consideración variables que no siempre constan fehacientemente en el proceso. Eso lleva a afirmar que siempre el juez tiene un espacio de bastante discrecionalidad en su decisión de decretar o no una medida cautelar. Y esa amplia discrecionalidad, está representada por la valoración de los presupuestos de la tutela cautelar que debe realizar en la causa.

Respecto del presupuesto de periculum in mora esa discrecionalidad aparece levemente restringida, porque el juez debe verificar si existen comprobantes que constituyan una presunción grave del derecho que se reclama. Obviamente, esa existencia de los comprobantes no libera al juez para valorar si el derecho en cabeza de quien solicita la medida existe, o aparezca verosímil su existencia. Un límite a esa discrecionalidad para el juez, viene representada porque sin esos comprobantes procede rechazar de plano la medida solicitada.

Por el contrario, en materia de peligro en la demora, el juez tiene un amplio poder para evaluar si existe un real peligro para los derechos e intereses del demandante mientras se ventila el proceso principal. Algo similar, existe en la ponderación de los derechos e intereses del demandante y demandado que están en juego.

En el caso de la exigencia de la caución, la situación es diversa. En este caso el juez debe valorar varias cosas: si decreta o no la caución y debe además valorar su suficiencia.

El tema de la exigencia de una caución a quien solicita una medida cautelar es quizás uno de los aspectos más complejos, pues en algún sentido puede significar una traba insalvable para obtener por parte del juez una medida cautelar, y así garantizar una tutela para el demandante que puede entenderse verdaderamente efectiva. En el apartado siguiente, analizaré cómo se regula la exigencia de caución en la ley y los problemas que trae aparejado. 


\subsection{La exigencia de caución como limitación a disponer de una adecuada tutela cautelar}

La legislación procesal civil chilena, obliga en algunos casos a quien solicita una medida cautelar a constituir una caución para responder por los eventuales daños que se causen a la persona que soporta la medida. Ello ocurre cuando una medida cautelar se solicita como medida prejudicial precautoria (Código de Procedimiento Civil, 1902, art. 279, no. 2). En otros casos, el juez está facultado para exigir o no esa caución, como ocurre cuando se solicita una medida cautelar o precautoria innominada (Código de Procedimiento Civil, 1902, art. 298). En el primer caso la ley exige perentoriamente constituir la caución y en el segundo esa exigencia es facultativa, lo que en cada caso debe ponderar el juez.

Los principales problemas relacionados con la constitución de una caución se refieren, en primer lugar, a que se su exigencia comporta muchas veces una traba $o$ limitación para un libre acceso a la justicia. Esa traba o limitación, puede deberse a que el demandante no tiene bienes o capacidad económica para rendir la caución. Con su exigencia, por tanto, se puede afectar el derecho fundamental a la tutela judicial de dicho demandante. En segundo lugar, existe una dificultad objetiva derivada de la determinación de los factores idóneos que deben ser considerados para su cuantificación. Por ello y por otras razones, los redactores del Código de Procedimiento Civil tenían una opinión negativa sobre la exigencia de una caución (Bordalí Salamanca, Cortéz Matcovich y Palomo Vélez, 2014, p. 471).

Y es entendible esa opinión negativa de la Comisión Redactora del Código de Procedimiento Civil hacia la caución, pues no se observa racionalidad en su no exigencia como hipótesis general, haciéndola facultativa cuando se trata de medidas innominadas, hasta hacerla siempre exigible si la medida se adopta antes de iniciarse el juicio. En este último caso, bastaría como garantía de seriedad, con la obligación del sujeto que solicita la medida prejudicial precautoria que presentase su demanda en el plazo de diez días, y que pidiese que se mantenga la medida durante la tramitación del proceso principal. La exigencia de caución aparece como una exigencia desproporcionada.

La posibilidad de exigir una caución en el caso de las cautelares innominadas se ha justificado por un sector de la doctrina en que, al no estar expresamente contempladas en la ley, requieren de mayores requisitos y el tribunal debe ser más exigente en su concesión (Quezada Meléndez, 1987, p. 108).

La opinión de esta doctrina, obedece a una concepción de la tutela cautelar en una lógica meramente legal, sin que ella haya sido ni siquiera imaginada en un contexto de exigencia constitucional como instrumento de una tutela judicial que debe dar el Estado a los individuos con plena efectividad. 
Por otro lado, se debe tener presente que la exigencia de caución está pensada en un contexto de contenciosos civiles patrimoniales, que fue los que ideó el legislador procesal civil del siglo XIX, que a su vez se inspiró en una legislación española que hunde sus raíces en la Novísima Recopilación y en las Partidas (Marín González, 2016, p. 156). Por ello, toda vez que las medidas cautelares puedan tener aplicación en contenciosos que no sean estrictamente patrimoniales, surge la duda de si su exigencia aparece justa y proporcionada.

En ese contexto, se puede decir que la exigencia de caución puede ser refutada. No se ve ninguna razón para entender que las precautorias nominadas del Código de Procedimiento Civil (1902, art. 290) se decreten sin caución, mientras que toda otra no expresamente prevista en la ley, del tipo que sea, pueda requerir caución. Se asume, en la tesis de esta doctrina, que las innominadas pueden producir más perjuicios que las nominadas. Sin embargo, no hay mayor argumentación que sostenga esta afirmación.

Un análisis racional de la situación debe invitar al juez a un análisis pormenorizado, y ver si una medida cautelar en concreto puede causar ese supuesto mayor daño y, si fuese así, atendido las particularidades del caso, ver si procede exigir caución o no.

Como cuestión de principio, se puede decir que no debería exigirse dicha caución cuando el derecho por el que se solicita tutela se refiere a bienes de nivel constitucional y, en particular, intereses esenciales de la persona. Lo mismo debería ocurrir cuando se discute sobre derechos e intereses legales de contenido no patrimonial.

No debe olvidarse, que las reglas sobre medidas cautelares reales del Código de Procedimiento Civil (1902) tienen aplicación en todo tipo de contenciosos no penales .

En el derecho comparado, poniendo énfasis en la idea de efectividad en la tutela de quien demanda, se ha sostenido que la exigencia de caución como instrumento de reequilibrio entre las posiciones de las partes en el proceso, en realidad solo puede ser exigida en aquellas controversias que tienen por objeto derechos de contenido y función prevalecientemente patrimoniales (Tommaseo, 2008, p. 176).

La lógica civil decimonónica de la tutela cautelar y los escenarios para exigir una caución, donde normalmente será un conflicto privado de carácter patrimonial entre Ticio y Cayo, no puede ser aplicada sin más a otros contenciosos. Un caso paradigmático, es un contencioso administrativo donde muchas veces se discute sobre la nulidad de un acto de la Administración. La naturaleza de los conflictos privados que está en la base del Código de Procedimiento Civil (1902), conflictos que son meramente patrimoniales y referidos a derechos divisibles en su inmensa mayoría, no 
puede ser trasladada mecánicamente a la esfera del contencioso administrativo de nulidad.

La tutela cautelar, cual exigencia constitucional en el mandato de efectividad de la tutela judicial, aplicada en un litigio contra la Administración del Estado, exige un análisis y consideraciones diversas.

\section{El derecho a la tutela cautelar en el contexto del contencioso ad- ministrativo}

\subsection{El contencioso administrativo y la tutela judicial de los administrados}

Debe destacarse, que el enfoque de Derecho Constitucional de la tutela cautelar emergió en el derecho comparado, precisamente desde el contencioso administrativo. Así fue en el caso de Italia (Tommaseo, 2008, p. 176).

En materia de tutela judicial, en el marco de un contencioso administrativo, se ha entendido que el mandato al legislador desde la Constitución implica que se debe prever la posibilidad de que un juez suspenda un acto administrativo cuando éste pueda producir un daño al particular afectado (véanse las sentencias del Tribunal Constitucional de España No 238/1992 y 148/1993, entre otras). Y en general se ha entendido que esa suspensión debe proceder sin más trabas legislativas, como podría ser la exigencia de una caución.

Se debe agregar, que la importancia de la tutela cautelar en la Justicia Administrativa va acompañada de un retroceso de la concepción objetiva de la misma y se inserta, al contrario, en una óptica subjetiva de tutela judicial efectiva de los derechos e intereses legítimos de los administrados (Bordalí Salamanca y Ferrada Bórquez, 2009, p. 187).

Si en virtud del Código de Procedimiento Civil, (1902, art. 38 inc. 2) el contencioso administrativo chileno no consiste en un mero control objetivo de legalidad de los actos de la Administración del Estado, sino en un proceso judicial contra la Administración que busca dar tutela a los derechos y también intereses legítimos de los administrados, la tutela cautelar debe ser puesta como primera línea de batalla para lograr que esa tutela que debe dar el Estado sea realmente efectiva.

Como en la Justicia Administrativa la tutela cautelar debe ser considerada desde otra perspectiva, años atrás sostuvimos que exigir cauciones para obtener una medida cautelar en un contencioso administrativo, carece muchas veces de lógica o bien de sentido. Y ello se da porque se está en un contencioso donde no figuran dos sujetos en términos de igualdad, pues se trata de un privado que litiga contra el Estado, en este caso la Administración del Estado. 
Muchas veces, los particulares no podrán tener la capacidad económica para constituir dicha caución. O bien, en otros casos, los demandantes no obtendrán ninguna prestación económica si su pretensión en definitiva es acogida, logrando dejar sin efecto un acto administrativo o impidiendo que se dicte éste.

Carece de toda razonabilidad que en virtud de las reglas del Código de Procedimiento Civil (1902), una medida cautelar de, por ejemplo, prohibición de celebrar actos y contratos solicitada por un demandante civil que cobra un crédito, no deba rendir caución, y que sí deba rendirla quien demande a la Administración del Estado para que se deje sin efecto un acto ilegal y arbitrario de esa entidad que afecta muchas veces a los derechos fundamentales de la persona del reclamante.

Por ello, es que los únicos presupuestos de la tutela cautelar en sede de justicia administrativa deben ser los del fumus y periculum in mora. También debemos agregar la proporcionalidad o principio de mínima injerencia, pero no como presupuesto sino como principio informador.

La caución solo puede ser exigida muy excepcionalmente, tomando en consideración la situación de los sujetos reclamantes y las pretensiones deducidas (Bordalí Salamanca y Ferrada Bórquez, 2009, p. 198). Por regla general, no tiene sentido su exigencia.

\subsection{La suspensión del acto administrativo como medida cautelar típica del contencioso administrativo}

Las medidas cautelares del contencioso administrativo, no se corresponden como hipótesis general con las medidas precautorias del Código de Procedimiento Civil. La medida cautelar por excelencia en el contencioso administrativo es la suspensión del acto. Esta será la primera medida perseguida y deseada por el demandante en un proceso administrativo, constituyendo un primer peldaño en la obtención de la anulación final del acto administrativo del que se impugna su legalidad.

De acuerdo con lo anterior, no corresponde hablar de la suspensión como una medida cautelar excepcional, innominada o especial. La suspensión del acto administrativo es la medida cautelar principal y por excelencia del contencioso administrativo.

Se ha llegado a sostener en el derecho europeo, que la suspensión del acto administrativo ha asumido la dignidad de un verdadero y propio estatuto constitucional.

En países como Francia, se considera a la suspensión del acto administrativo como parte del bloque de constitucionalidad y por tanto como un límite a la actuación del propio legislador (Carducci, 2000, p. 93). 
En Alemania, se ha arribado a una situación en que la suspensión del acto administrativo, por regla general, opera automáticamente con la interposición del recurso jurisdiccional (Tarullo, 2004, p. 544).

En Chile, la suspensión del acto aparece como el instrumento cautelar asociado a la hipótesis más general de nulidad del derecho chileno, como lo es la Nulidad de Derecho Público. En otros contenciosos de nulidad que tienen una regulación legal especial, la suspensión del acto administrativo también aparece como la medida más idónea para dar tutela judicial efectiva al demandante.

Pero como la Nulidad de Derecho Público carece de una regulación legal expresa, la medida cautelar de suspensión obliga a ser analizada como aplicación de las medidas innominadas del Código de Procedimiento Civil (1902, art. 298), por aplicación supletoria del juicio ordinario civil (Código de Procedimiento Civil, 1902 art. 3).

He aquí la principal dificultad con que se encuentran los administrados que necesitan recurrir ante la jurisdicción, para que ésta los tutele en sus derechos o intereses legítimos. El legislador administrativo o procesal administrativo, no ha dado desarrollo al derecho fundamental a la tutela judicial.

Pero ese defecto del Estado chileno, en este caso en su sección como ente legislativo, no puede traducirse en un perjuicio para los administrados. Y es deber de los jueces velar porque esa insuficiencia normativa no se traduzca en ese temido perjuicio para los particulares, afectando sus derechos fundamentales. En eso consiste la labor de garantía que tienen los jueces (Ferrajoli, 2007, p. 872).

Los jueces tienen el deber, frente a las omisiones del legislador, de interpretar las disposiciones legales de una manera favorable a los derechos fundamentales de los particulares (Constitución Política de la República, 2005, arts. 5 y 6).

En general los jueces civiles chilenos no han asumido ese deber de tutela de los derechos fundamentales en la tramitación e interpretación de las normas procesales aplicables a un caso. Lo anunciábamos años atrás del siguiente modo.

En efecto, los jueces [civiles] son tradicionalmente reacios a otorgar medidas cautelares innominadas en los procesos judiciales y en los casos que las conceden, en general, exigen contracautela para hacerla procedente. Tal criterio evidentemente no tiene sentido en el ámbito administrativo, donde la caución es de difícil determinación o, en los casos que es posible hacerlo, su monto constituiría un obstáculo insalvable para la tutela efectiva de los derechos de los administrados. (Bordalí Salamanca y Ferrada Bórquez, 2009, p. 207)

Por ello es que se requiere de otra mirada en el otorgamiento de medidas cautelares en el contencioso administrativo, que escape a la lógica de un conflicto 
La caución como requisito para conceder una medida cautelar...

civil entre particulares. Se requiere de una mirada constitucional y de proyección pública; desde luego, también administrativa.

Ya hemos adelantado una situación muy particular que considera la doctrina contemporánea. La concesión de una medida cautelar no puede aparecer condicionada a la constitución de una caución, cuando la medida se refiera a derechos fundamentales de la persona o a otros bienes de nivel constitucional (Casetta y Fracchia, 2017, p. 217).

El Tribunal Constitucional se ha hecho eco de esta situación que describimos. En efecto, por sentencia de fecha 14 de mayo de 2019, en la causa Requerimiento de inaplicabilidad por inconstitucionalidad presentado por Concesiones Recoleta S.A. (2019) Rol N 3819-17, el referido tribunal declaró inaplicables para una causa pendiente ante la Corte de Apelaciones de Santiago, Código de Procedimiento Civil (1902, art. 279 , no. 2 y 298$)$.

Recordemos que esas disposiciones legales señalan, respectivamente:

Podrán solicitarse como medidas prejudicales las precautorias de que trata el Título $V$ de este Libro, existiendo para ello motivos graves y calificados, y concurriendo las circunstancias siguientes: [...]

2a. Que se rinda fianza u otra garantía suficiente, a juicio del tribunal, para responder por los perjuicios que se originen y multas que se impongan. (Código de Procedimiento Civil, 1902, art. 279)

Luego la otra disposición establece que

Las medidas de que trata este Título se limitarán a los bienes necesarios para responder a los resultados del juicio; y para decretarlas deberá el demandante acompañar comprobantes que constituyan a lo menos presunción grave del derecho que se reclama. Podrá también el tribunal, cuando lo estime necesario y no tratándose de medidas expresamente autorizadas por la ley, exigir caución al actor para responder de los perjuicios que se originen. (Código de Procedimiento Civil, 1902, art. 298)

La sentencia en cuestión del Tribunal Constitucional, vincula el derecho a la tutela judicial o derecho a la acción con la posibilidad del actor de obtener una medida cautelar que permita que la sentencia que en su día pudiese dictarse a su favor, pueda cumplirse en sus propios términos y así, ver satisfechos sus derechos e intereses materiales.

El problema se planteó acá porque la demandante, en sede de justicia ordinaria, solicitó como medida prejudicial precautoria la suspensión de un acto administrativo de la I. Municipalidad de Recoleta. Todo ello en el contexto de un proceso para que se declare la Nulidad de Derecho Público del acto municipal. El juez de la instancia denegó la medida prejudicial precautoria, por cuanto se vio imposibilitado 
de fijar un monto de una caución en un proceso que no tiene una cuantía clara desde el punto de vista patrimonial. En definitiva, la existencia de una caución vino a ser el obstáculo para ese juez de la instancia de decretar la medida prejudicial precautoria de suspensión del acto administrativo.

Desde luego, se puede discutir si la referencia a la caución que contempla el Código de Procedimiento Civil (1902, art. 298) imposibilitó verdaderamente el otorgamiento de la medida cautelar, toda vez que no es un imperativo para el juez exigirla. En este sentido, si el juez tuvo problemas con la determinación del monto de la caución que debía constituir el actor, podría haber prescindido de la misma y no exigirla. Por este camino recorre el voto de minoría del fallo en cuestión.

Sin embargo, el voto de mayoría es relevante para vincular a la tutela cautelar como componente del derecho a la tutela judicial que pueda calificarse de efectiva. La ley no debe poner trabas innecesarias o desproporcionadas a la obtención de medidas cautelares, pues pueden impedir que los ciudadanos puedan lograr una tutela judicial por parte del Estado que realmente ampare sus derechos e intereses.

De especial relevancia son los considerandos del referido fallo que citaré a continuación:

SEGUNDO: Que, de esta manera aplicadas las normas cuestionadas, es evidente que ambas producen un resultado contrario a la Constitución. Si ésta ha querido que todos los derechos, en general, gocen de eficacia práctica y real, con mayor razón habrá de poder ejercerse con todo provecho o utilidad el derecho a la acción, cuya funcionalidad consiste esencialmente- en que los tribunales puedan brindar por su intermedio una defensa efectiva a aquellos otros derechos garantidos por la Constitución.

Una ley, entonces, que veda al juez la facultad de paralizar la ejecución de un acto administrativo mientras se discute su validez, o que entable para el justiciable condiciones o requisitos que impiden su obtención, al tolerar -en ambos casos- que una eventual sentencia anulatoria llegue a carecer de toda trascendencia real, contraviene los preceptos constitucionales que en seguida se señalan. [...]

QUINTO: [...] [la acción es] Un derecho cuyo ejercicio resultaría meramente ilusorio, si se cierra la posibilidad de adoptar medidas cautelares que aseguren el efectivo cumplimiento de cuanto se resuelva en definitiva. Pues una eventual sentencia favorable carecería de toda virtualidad, transmutando en un documento meramente decorativo, si la autoridad demandada, intertanto se tramita el proceso, se anticipa a los resultados del juicio haciendo ejecutar el acto reclamado y avocándose de esta suerte la respectiva causa pendiente. (Requerimiento de inaplicabilidad por inconstitucionalidad presentado por Concesiones Recoleta S.A., 2019, cons. 2 y 5 ) 
La caución como requisito para conceder una medida cautelar...

Hay que tener presente, que los jueces de la instancia no cuentan con información ni mecanismos que les permitan precisar el monto de una caución que puede exigirse, para que se decrete una medida cautelar de suspensión u otra innominada en un contencioso administrativo de nulidad. Ello ocurre, entre otras razones, porque es extremadamente difícil fijar la cuantía de la caución si la demanda principal no tiene un valor económico preciso. Y al no poder fijar la caución, en algunos casos, como aquél en que recayó la sentencia de inaplicabilidad antes citada, los jueces optan por rechazar la petición de medida cautelar. Con ese actuar, dichos jueces dejan sin tutela judicial efectiva a los justiciables.

Hay que tener presente, que el Código de Procedimiento Civil (1902, art. 298) no exige perentoriamente a los jueces constituir una caución a cargo del actor que solicita una medida cautelar de suspensión u otra medida innominada. Exigir esa garantía es facultativo para los jueces. Si el juez se ve con dificultad para determinar qué caución debe exigir y si observa que la medida cautelar solicitada es esencial para evitar la posibilidad de que los derechos e intereses del actor queden insatisfechos, pues entonces debe decretar la medida cautelar y no exigir caución.

Llevado a un plano más general, tratándose del contencioso administrativo chileno general, donde no hay una regla especial referida a las medidas cautelares, lo que hace que deban aplicarse supletoriamente las reglas de las medidas precautorias del Código de Procedimiento Civil (1902), la orden de suspensión debería proceder como regla general, sin que se deba exigir constituir una caución.

Solo si el juez considera no verosímil la pretensión del actor o si considera plausible que al no decretar la medida cautelar no se verán perjudicados los derechos e intereses de ese actor, entonces podrá denegar la medida o bien acceder a ella previa constitución de una caución. Será deber del juez realizar un cuidadoso análisis de los presupuestos del fumus boni iuris y del periculum in mora en la concreta situación que debe resolver.

Sería deseable, por tanto, que el legislador regulara estos criterios en alguna disposición legal más general referida al contencioso administrativo. Sin embargo, será difícil que ello pueda ocurrir en nuestro sistema normativo, porque ello aparece asociado a la existencia de un contencioso administrativo general o a la creación de los tribunales de lo contencioso administrativo. Nada de ello se ve cercano en nuestro ordenamiento jurídico actual.

Mientras tanto, muchos contenciosos administrativos seguirán tramitándose por jueces civiles y con una legislación procesal civil. El problema que se presenta, es que esos jueces tienen que operar con esa legislación procesal decimonónica que tiene sus raíces en el derecho español medieval, y que está pensada para conflictos patrimoniales entre dos sujetos que se encuentran en una relativa posición de igualdad. 
Ahora bien, que el legislador no haya desarrollado el contencioso de nulidad con un carácter general y que en él no se prevea la medida de suspensión del acto administrativo impugnado como medida típica, con una operatividad de pleno derecho o como hipótesis general, sin caución, no puede traducirse en un perjuicio para los administrados que ven así vulnerados sus derechos fundamentales.

Corresponde al Tribunal Constitucional velar porque tal injusticia o efectos inconstitucionales de tal omisión estatal, no se produzcan en gestiones judiciales pendientes. Es precisamente lo que acaba de hacer el Tribunal Constitucional en la sentencia recientemente citada.

Pero antes que el Tribunal Constitucional, corresponde a los jueces del fondo dar una interpretación al Código de Procedimiento Civil (1902), de modo tal que se garantice siempre la tutela judicial efectiva de los derechos e intereses legítimos de los demandantes. Ello es posible, y está dentro del marco constitucional y legal de su accionar.

Como ha dicho Marinoni (2007),

...si la técnica procesal es imprescindible para la efectividad de la tutela de los derechos, no se puede suponer que, ante una omisión del legislador, el juez nada puede hacer. Esto por una razón simple: el derecho fundamental a la efectividad de la tutela jurisdiccional no se vuelve solo contra el legislador, sino también se dirige contra el Estado - juez. Por ello, es absurdo pensar que el juez deja de tener el deber de tutelar de forma efectiva los derechos solamente porque el legislador dejó de establecer una norma procesal más explícita. (p. 280).

Y luego agrega este mismo autor:

... hay que entender que el ciudadano no tiene un simple derecho a la técnica procesal evidenciada en la ley, sino un derecho a un determinado comportamiento judicial que sea capaz de conformar una regla procesal acorde con las necesidades del derecho material y con los casos concretos (Marinoni, 2007, p. 281).

Lo afirmado por Marinoni (2007) es tomarse en serio la Constitución y la idea de que el Estado debe dar una tutela judicial realmente efectiva a las personas. Todo ello supone una especial carga para los jueces, que deben realizar un trabajo mucho más arduo, teniendo muchas veces que realizar interpretaciones de la ley procesal de conformidad con los mandatos constitucionales, para así suplir las omisiones o derechamente la pereza del legislador.

La solución definitiva pasa porque el legislador regule con detalle un contencioso administrativo y, dentro de él, unas específicas medidas cautelares y sus presupuestos. Mientras no suceda ello, son los jueces los que deben hacer real el derecho 
La caución como requisito para conceder una medida cautelar...

fundamental de los ciudadanos a obtener tutela judicial efectiva para sus derechos e intereses legítimos.

\section{Conclusiones}

Hoy en día es cada vez más claro que la Constitución Política de la República (2005, art. 19 , no. 3 , inc. 1 ) reconoce como derecho fundamental de las personas un derecho a la tutela judicial. Ese derecho, no solo garantiza un acceso de todas las personas para pedir tutela a los tribunales para un derecho o interés que les pertenezca, y una respuesta por parte de dichos órganos públicos a esa solicitud de tutela. Lo que demanda el referido derecho, es que la tutela judicial no se limite a una pura respuesta nominal por parte de los tribunales, sino que reclama una efectiva y concreta protección para esos derechos e intereses.

En virtud de lo anterior, corresponde en primer lugar al legislador crear las herramientas cautelares que permitan a los jueces decretarlas para dar una efectiva tutela a los derechos e intereses de los demandantes. Pero en todo caso, con o sin una regulación legal adecuada, los jueces que conocen del contencioso civil y administrativo deberán interpretar la ley procesal de un modo tal que resulte siempre favorable a la integridad de los derechos e intereses de los justiciables.

En el contencioso administrativo de nulidad del derecho chileno, en el que se deben aplicar supletoriamente las reglas sobre las medidas precautorias del Código de Procedimiento Civil (1902), los jueces de la instancia deben mostrarse favorables a decretar como medida cautelar innominada la suspensión del acto administrativo, sin exigir una caución. Solo si estiman que la pretensión de actor no aparece enteramente plausible, o si llegan a una cierta convicción de que los derechos o intereses del actor no sufrirían una desprotección en caso de no contar con una medida cautelar, podrían denegar ésta, o bien exigir una caución.

La conclusión final, es que hoy en día la tutela cautelar en asuntos no penales es una institución que no solo tiene reconocimiento legal, sino que se impone por un imperativo constitucional referido a la plena vigencia de los derechos fundamentales de las personas. Esa perspectiva de derechos fundamentales, impone al legislador regular de mejor manera la batería de herramientas cautelares con que deben contar los justiciables en un proceso y, además, obliga a los jueces a decretar con más propiedad medidas cautelares en favor de los derechos e intereses de los actores. Hace necesario, también, interpretar los preceptos legales de orden procesal siempre de un modo más favorable a la efectiva tutela que deben recibir por parte del Estado las personas. 


\section{Referencias Bibliográficas}

Arnold, R., Martínez Estay, J. I. y Zúñiga Urbina, F. (2012). El principio de proporcionalidad en la jurisprudencia del Tribunal Constitucional. Estudios constitucionales, 10(1), 65-116. doi: 10.4067/S0718-52002012000100003

Bordalí Salamanca, A. (2002). Temas de derecho procesal constitucional. Santiago: Fallos del Mes.

Bordalí Salamanca, A. (2011a). Análisis crítico de la jurisprudencia del Tribunal Constitucional sobre el derecho a la tutela judicial. Revista chilena de derecho, 38(2), 311337. doi: $10.4067 /$ S0718-34372011000200006

Bordalí Salamanca, A. (2011). La acción penal y la víctima en el Derecho chileno. Revista de derecho (Valparaíso), (37), 513-545. doi: 10.4067/S0718-68512011000200013

Bordalí Salamanca, A. (2016). Derecho Jurisdiccional. Valdivia: Derecho Austral.

Bordalí Salamanca, A. y Ferrada Bórquez, J. C. (2009). Estudios de justicia administrativa. Santiago: Legal Publishing.

Bordalí Salamanca, A., Cortéz Matcovich, G. y Palomo Vélez, D. I. (2014). Proceso civil. El juicio ordinario de mayor cuantía, procedimiento sumario y tutela cautelar (2a ed.). Santiago: Thomson Reuters.

Calamandrei, P. (1996). Introducción al estudio sistemático de las providencias cautelares. Buenos Aires: Librería El Foro.

Carducci, M. (2000). La sospensione cautelare dell'atto amministrativo come parte del blocco di costituzionalità. En E. Rozo Acuña (Ed.), Cittadino e amministrazione nel diritto comparato (pp. 91-105). Nápoles: Scientifiche Italiane.

Casetta, E. y Fracchia, F. (2017). Giustizia amministrativa. Milán: Giuffrè.

Cipriani, F. (2007). El procedimiento cautelar entre eficiencia y garantías. En A. de la Oliva Santos y D. Palomo Vélez (Coords.), Proceso civil: hacia una nueva justicia civil (pp. 295-317). Santiago: Jurídica de Chile.

Constitución Política de la República. Diario Oficial de la República de Chile, Santiago, Chile, 22 de septiembre de 2005. Recuperado de http://bcn.cl/2f6sk

Cortéz Matcovich, G. (2017). La tutela cautelar en el proceso civil. Santiago: Thomson Reuters.

Cuestión de inconstitucionalidad 1.445/1987. En relación con el art. 6.2 de la Ley 34/1979, de 16 de noviembre, de Fincas Manifiestamente Mejorables, N 238/1992 
La caución como requisito para conceder una medida cautelar...

(Tribunal Constitucional de España 17 de diciembre de 1992). Recuperado de https://bit.ly/3i32M7p

Ferrajoli, L. (2007). Principia iuris. Teoria del diritto e della democrazia. Teoria del diritto (Vol. 1). Roma: Laterza.

García Pino, G. y Contreras Vásquez, P. (2013). El derecho a la tutela judicial y al debido proceso en la jurisprudencia del Tribunal Constitucional chileno. Estudios constitucionales, 11(2), 229-280. doi: 10.4067/S0718-52002013000200007

Giudizio di legittimità costituzionale in via incidentale, N 190/1985 (La Corte Costituzionale 28 de junio de 1985). Recuperado de https://bit.ly/3c4XX9S

Ley $\mathrm{N}^{\circ}$ 1552. Código de Procedimiento Civil. Diario Oficial de la República de Chile, Santiago, Chile, 30 de agosto de 1902. Recuperado de http://bcn.cl/2f6oc

Marín González, J. C. (2016). Tratado de las medidas cautelares: doctrina, jurisprudencia, antecedentes históricos y derecho comparado (Vol. 2). Santiago: Jurídica de Chile.

Marinoni, L. G. (2007). Derecho fundamental a la tutela jurisdiccional efectiva: del proceso civil clásico a la noción de derecho a la tutela jurisdiccional efectiva (A. Zela Villegas, Trad.). Lima: Palestra.

Ortells Ramos, M. y Calderón Cuadrado, M. P. (1996). La tutela judicial cautelar en el Derecho español. Granada: Comares.

Ortells Ramos, M. (2007). Derecho procesal civil (7a ed.). Cizur Menor: Aranzadi.

Quezada Meléndez, J. (1987). Derecho procesal chileno: medidas prejudiciales y precautorias. Santiago de Chile: Conosur.

Rapisarda Sassoon, C. (1987). Profili della tutela civile inibitoria. Padua: CEDAM.

Recurso de amparo 1.299/1991. Contra Auto de la Audiencia Provincial de Barcelona inadmitiendo recursos de queja frente a resoluciones del Juzgado de Instrucción núm. 2 de Granollers que rechazaron la pretensión de la actora para comparecer como parte en proceso penal. Supuesta vulneración del derecho a la tutela judicial efectiva: incumplimiento de requisito procesal, N²7/1995 (Tribunal Constitucional de España 6 de febrero de 1995). https://bit.ly/34wKvHz

Recurso de amparo 2.416/1990, Confederación Sindical de Comisiones Obreras contra Auto, en vía de apelación, de la Sala Tercera del Tribunal Supremo, declarando improcedente la suspensión de las órdenes dictadas por la Junta de Andalucía con ocasión de la huelga general convocada y destinadas a garantizar la prestación de servicios mínimos. Vulneración de los derechos a la tutela judicial efectiva y a la huelga. $N^{\circ} 148 / 1993$, (Tribunal Constitucional de España 29 de abril de 1993). Recuperado de https://bit.ly/3p5YGg9 
Recurso de amparo 2.566/1991 contra Auto de la Audiencia Provincial de Barcelona, recaído en apelación que confirmó el dictado por el Juzgado de Primera Instancia núm. 9, de la misma ciudad, en incidente de oposición sobre medidas cautelares acordadas en juicio de menor cuantía, sobre nulidad de marcas, cesación de su uso y otros extremos. Supuesta vulneración del derecho a la tutela judicial efectiva: Medidas cautelares no causantes de indefensión, № 218/1994 (Tribunal Constitucional de España 18 de julio de 1994). Recuperado de https://bit.ly/3wJt0zN

Recurso de amparo 2.698/1993. Contra Sentencia de la Sala de lo ContenciosoAdministrativo del T.S.J. de la Comunidad Valenciana que desistimó recurso deducido al amparo de la Ley 62/1978 contra Resolución sobre ejecución de sanción disciplinaria del Director del Hospital General de Alicante. Vulneración del derecho a la tutela judicial efectiva: ejecución de sanción no firme, N 78/1996 (Tribunal Constitucional de España 20 de mayo de 1996). Recuperado de https://bit.ly/3vCsL9G

Requerimiento de inaplicabilidad por inconstitucionalidad presentado por Concesiones Recoleta S.A. respecto de los artículos 279 y 298 del Código de Procedimiento Civil, en los autos sobre recurso de apelación de incidente, caratulados "Concesiones Recoleta S.A. con I. Municipalidad de Recoleta", de que conoce la Corte de Apelaciones, bajo el Rol N6000-2017, Rol N³819-17 (Tribunal Constitucional de Chile 14 de mayo de 2019). Recuperado de https://bit.ly/3wKkxwb

Tarullo, S. (2004). Il giusto processo amministrativo: studio sull'effettività della tutela giurisdizionale nella prospettiva europea. Milán: Giuffrè.

Tommaseo, F. (2008). II fondamento costituzionale della tutela cautelare. En F. Cipriani (Ed.), Stato di diritto e garanzie processuali (pp. 165-186). Nápoles: Scientifiche Italiane.

\section{Para citar este artículo bajo Norma APA 6a ed.}

Bordalí Salamanca, A. (2021). La caución como requisito para conceder una medida cautelar: su no exigibilidad en materia contenciosa administrativa. Revista de derecho (Coquimbo. En línea), 28, e3644. https://doi.org/10.22199/issn.0718-97532021-00014

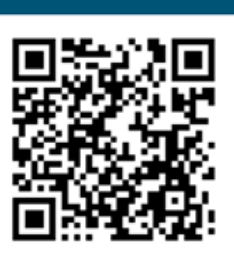

Este es un artículo de acceso abierto, bajo licencia Creative Commons BY 4.0. 